\title{
Social Influence from Personalized Recommendations to Trusting Beliefs of Websites: Intermediate Role of Social Presence
}

\author{
Yanan $\mathrm{Li}^{1,2}$ and Yong Wang ${ }^{1, *}$ \\ ${ }^{1}$ Institute of Psychology, Chinese Academy of Sciences, 16 Lincui Road, \\ 100101 Beijing, China \\ ${ }^{2}$ University of Chinese Academy of Sciences, 19 Yuquan Road, 100049 Beijing, China
}

\begin{abstract}
With the increasing prevalence of online shopping, many companies have added "personalized recommendation" modules on their websites to collect customers' click-stream data in real time and conduct relevant analysis, which will both assist the decision-making of the web owners and enrich the interactive experience of the customers. A website with more personalized recommender system allows users to experience others as psychologically present being, conveys a feeling of human warmth and sociability which is believed critical for the formation of consumers' trust towards online stores. In this study, a laboratory experiment was conducted to empirically examine the effects of the level of perceived personalization on consumers' trusting beliefs towards online store. The result also demonstrated that the perception of social presence can partially mediate the effect of perceived personalization on consumer's trusting beliefs.
\end{abstract}

Keywords: Personalized Recommendation, Personalization, Social Presence, Trusting beliefs.

\section{Introduction}

Web interface, the bridge between websites and consumers, not only undertakes the practical task, but also works as an emotional bond, bringing unique experience to form a social connection between websites and customers. Websites with personalized recommender system, with Amazon.com as the representative, learn consumers' preferences based on the click-stream data, so as to achieve a personalized presentation. Personalized recommending helps consumers to screen items they might be interested in from numerous commodities, and reduces information overload and increases choice efficiency. At the same time, it realizes the goal of persuading consumers by influencing their choice and preference $[1,2]$.

Apart from the practical functions mentioned above, the scenario of a one-on-one conversation is created between consumer and website during the recommending process, thereby generating a feeling that he/she is "being with other people". This is

\footnotetext{
* Corresponding author.
} 
the foundation for the forming of the perception of social presence. Many investigations show that social presence is a key factor influencing the consumer trust towards the website [3, 4]. Previous studies, however, rarely discuss how it is affected by personalized recommendations. This study aims to investigate the effect of personalized recommendation on the consumers' trusting beliefs towards the website and the role played by the perception of social presence in this process.

\section{$2 \quad$ Literature Review}

\subsection{Personalized Recommendation}

Personalized recommendation is a representative of personalized service [5]. Most early recommendations are generated by asking about customers' preferred commodity attributes in advance. As the recommendation algorithm keeps improving and data mining technology is making advances, personalized recommender system as represented by Amazon.com can achieve real-time indirect conjecture on consumer demand based on click-stream data. Compared with earlier strategy, this contextbased recommendation strategy moves closer towards personalization.

A personalized recommender system helps in alleviating information overload, improving choice efficiency, and enabling cross- and up- selling. Besides, it also influence consumers' cognitive processing and decision-making [6], their evaluation [7] and satisfaction, loyalty and trust to the website.

Researchers have been devoting to increase the accuracy of recommending algorithm. The bottleneck in this process is mainly associated with the constructive nature of consumers' preference. While evaluating personalization level, there is no baseline website to compare against, regardless of the recommendation method used. Consumers' perception of personalization varies depending on the tasks, context and time. So personalization is not a technical term, but a psychological variable. According to psychological theory, the information more relevant to the consumers' goal will result in more perceived personalization and deeper cognitive processing, which is the essence of web personalization [7].

\subsection{Perception of Social Presence}

The notion of social presence refers to that, in the process of communication, the media of communication gives the individual a social feeling that he/she is "being with other people". In its nature, the perception of social presence is closely related to two psychological concepts: Intimacy and Immediacy.

In earlier studies, the factors identified as triggering the perception of social presence include emotional texts, images, personalized greetings, as well as information technology(IT)-enabled support for the provision of live chats, forums, consumer reviews, live help, and virtual reality technology, etc. It has been revealed that the perception of social presence causes more positive assessment on the efficacy of website, the satisfaction, pleasure experience and intention to use [8]. However, few 
researchers investigate the effect of perceived personalization on the perception of social presence [8].

\subsection{Trusting Beliefs towards Websites}

Unlike traditional context, shopping online seems to be deficient in human touch. It is more difficult but more important to build consumer's trust towards online store. McKnight, Choudhury and Kacmar [9] believe that, in the context of online shopping, the trust towards a website consists of trusting beliefs and trusting intention. Trusting beliefs, reflecting consumer's concrete cognition and emotional belief towards the seller, can directly lead to trust intention and trust-related behavior.

In previous studies on user adoption of personalized recommendation, trust is a key psychological variable. Personalized recommendations can facilitate the formation of trust by improving the transparency, perceived control and internalization.

Some studies suggest that personalization can result in emotional sense or affective experience, like feelings of intimacy, perception of social presence [1], which can improve trusting beliefs towards online store. Therefore, it is a new trend of research to put emphasis on the emotional bond between the consumer and website, and on the formation of trust from the social aspect.

\section{$3 \quad$ Hypothesis Development}

Kumar and Benbasat [7] are among the first to have discussed the difference between personalized and non-personalized websites in creating users' perception of social presence. They filtered Amazon.com's contents in real time in laboratory experiment, and found that the personalized recommender service in Amazon.com improves its social presence. The study conducted by Choi et al [8] manipulated the recommendation pages with varying levels of personalization according to the connections between the recommendation source and the consumer, in order to explore the influence of products recommendations with different personalization levels on the perception of social presence and intention to use. The results indicated that, compared with nonpersonalized recommendation (for example, ranking lists), users experienced a higher level of social presence in personalized recommendation page.

We believe that the higher the personalization level perceived by consumers from a website, the more likely the consumers feel involved in a one-to-one dialogue between him/her and the website. The intimacy and sociability easily create a warm feeling, i.e. the perception of social presence. Hence we make the following hypotheses:

\section{Hypothesis 1: Recommendation webpages with higher personalization level strengthens the consumer's perception of social presence.}

The content, presentation, and timing affect and what the consumer feels about the personalization level of the recommendation, influence his/her judgments on the website. Previous studies mostly focus on the recommendation agencies which acquired information of user preference explicitly. It shows that consumers develop higher 
cognitive trust and emotional trust towards the website when their perception of personalization is higher [10]. Moreover, the stronger the perception of personalization, the more precise, in the consumer's point of view, the website's conjecture on his/her preferences would be, which enhances his/her trusting beliefs towards the website. Hence,

\section{Hypothesis 2: Recommendation webpages with higher personalization level provoke stronger trusting beliefs from the consumers.}

Through previous studies, it is not difficult to conclude that the perception of social presence is a key intervening variable in the process of users reading through the web interface elements to affect the user trust $[3,4]$. In this study, further test is made to see whether user's perception of social presence will mediate the influence of perceived personalization on trusting beliefs towards the website. Hence,

\section{Hypothesis 3: The perception of social presence mediates the influence of personalization on trusting beliefs.}

\section{$4 \quad$ Research Methodology}

The task for the experiment consisted of asking participants to imagine that he/she is going to do some information searching for what he/she needs to buy, then browse web pages of a prototype shopping website named "Orangeebuy.com". The study was designed as a one-factorial experiment manipulating two levels of perceived personalized in two independent groups. Participants were randomly assigned to the two groups, where each participant was exposed to only one level of stimulus or condition.

The prototype site was designed in terms of content and page layout to resemble typical e-commerce sites, such as Amazon.com. Product introduction page displayed basic product information of one item, followed by a set of recommendations-8 similar products-preceded by the words "products recommended". For each condition, three product introduction pages involving three items, namely, headphone, TOEFL book and walnut, which were chosen in earlier studies [3, 8], were displayed. In order to confirm that the three items were within the scope of online shopping for college students in Beijing, an online questionnaire survey of about 200 undergraduates in Beijing was conducted. The results showed that books, digital devices and snack food were the top three product categories they most frequently purchased, and we also identified the commodity properties of the three items (price, brand, etc.) that the students were mostly concerned about when purchasing online.

All conditions, featured the same information of product introduction, but differed only in terms of recommendations. Following the strategy of "goal-relevance", which is considered as the major feature of e-personalization [2], participants in Group ${ }_{\text {High }}$, received more relevance recommendations to the product being introduced on current page based on the commodity property identified before than those in Group Low $_{\text {. }}$

Following the completion of the task in the main experiment, all items were statements and subject responses were offered on a 7-point Likert scale ranging from Strongly Agree(1) to strongly disagree(7). All the measuring scales were previously 
validated, including scale for Trusting beliefs [4, 9], scale for perceived personalization [10], and scale for social presence [3] and measuring for demographical profiles. Each participant would get a reward of $10 \mathrm{RMB}$ and some candies.

\section{Data Analysis}

A total of 114 undergraduates successfully completed the main experiment. Among

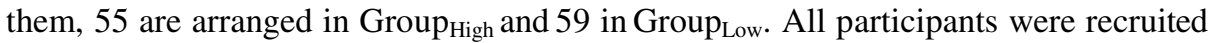
from universities in Beijing, China, including 39 males and 75 females with an average age of 23.5 years old. All participants reported that they had online shopping experience.

An independent-samples' t-test shows that the average score of perceived personalization between Group $\mathrm{High}_{\text {and }}$ and Group $_{\text {Low }}$ is significantly different $\left(\operatorname{Mean}_{\text {Low }}=4.76\right.$, Mean $\left._{\text {High }}=5.65, \mathrm{t}=5.172, p<0.001\right)$, which means that the experimental manipulation is successful.

We perform confirmatory factor analysis using AMOS 18.0 on the measurement model to assess internal consistency reliability, convergent validity, and discriminant validity. Trusting beliefs are represented as a second-order reflective construct, with benevolence, competence, and integrity beliefs represented as first-order reflective constructs [9]. Following the procedures recommended by Gorsuch, a first-order confirmatory factor analysis is used to confirm the structure of the three dimensions of trusting beliefs. The result shows, $\chi^{2} / d f=1.782$, NNFI $=0.906, \mathrm{CFI}=0.955$, RMSEA $=0.083$; the correlation coefficient of three sub-dimensions is $0.4 \sim 0.7(0.65$, $0.65,0.48)$. In second-order analysis, the model fitting indexes are also acceptable. But the correlations between second- and first-order factors are stronger $(0.66,0.67$, 0.96). Therefore, Trusting Beliefs as a second-order reflective construct can sufficiently express the concept connotation with a convenience of model simplification by averaging items from three sub-dimensions scales to represent the Trusting Beliefs.

A reliability test is conducted with an internal consistency test (Cronbach's alpha). The measurement items used in this study are shown to be reliable in that Cronbach's alpha values for all dimensions are at least 0.7 . Then, the convergent and discriminant validity of the constructs are assessed and suggested to be acceptable as described in Table 1 and 2.

To test the hypotheses, we test the perception of social presence and trusting beliefs between the two groups using One-way ANOVA. It is found that significant difference exists (Social Presence: $\operatorname{Mean}_{\mathrm{Low}}=3.97, \mathrm{SD}_{\mathrm{Low}}=0.96, \mathrm{Mean}_{\mathrm{High}}=4.68$, $\mathrm{SD}_{\text {High }}=1.19, \mathrm{~F}_{\text {social presence }}=11.923$, sig. $=.001$; Trusting Beliefs: $\operatorname{Mean}_{\text {Low }}=4.49$, $\mathrm{SD}_{\mathrm{Low}}=1.02, \mathrm{Mean}_{\mathrm{High}}=5.12, \mathrm{SD}_{\mathrm{High}}=0.71, \mathrm{~F}_{\text {trusting beliefs }}=13.992$, sig. $=.000$ ). Thus, Hypothesis 1 and Hypothesis 2 are confirmed. That is, recommendation webpages with higher personalization level can create a stronger perception of social presence and trusting belief.

In all of the regression analyses that follow, we first enter a series of control variables before testing Hypothesis 3. These control variables include gender, age, 
education, hours spent on Internet per day, and shopping frequency in recent three months.

To test for mediation, we use the following four-step procedure outlined by Baron and Kenny (see Table 3): Model 1 shows that Perceived Personalization is significantly related to Social Presence $(\beta=0.548, p<0.001)$. Model 2 suggests that Perceived Personalization is significantly related to Trusting beliefs $(\beta=0.608, p<0.001)$. Model 3 shows that Social Presence is significantly related to Trusting beliefs $(\beta=0.502$, $p<0.001)$. Support for the mediation hypothesis would be observed if the initially significant relationships we find between Perceived Personalization and Trusting beliefs disappear or decrease after we add Social Presence into the regression equation. Model 4 indicates that after Social Presence is added to the regression model, the initially significant relationship between Perceived Personalization and Trusting beliefs does not disappear $(\beta=0.440, p<0.001)$. This result suggests that Social Presence only partially mediates the relationship between Perceived Personalization and Trusting beliefs. Thus, Hypothesis 3 is confirmed.

Table 1. Results of Reliability and Convergent Validity Analysis

\begin{tabular}{|c|c|c|c|c|c|}
\hline Items & $\begin{array}{l}\text { Standardized } \\
\text { loadings }\end{array}$ & $\begin{array}{l}\text { Cronbach's } \\
\text { alpha }\end{array}$ & Items & $\begin{array}{l}\text { Standardized } \\
\text { loadings }\end{array}$ & $\begin{array}{l}\text { Cronbach's } \\
\text { alpha }\end{array}$ \\
\hline PP1 & 0.755 & 0.778 & $\mathrm{TBb} 1$ & 0.709 & 0.808 \\
\hline PP2 & 0.889 & & $\mathrm{TBb} 2$ & 0.803 & \\
\hline PP3 & 0.600 & & $\mathrm{TBb} 3$ & 0.790 & \\
\hline SP1 & 0.791 & 0.877 & TBI1 & 0.875 & 0.915 \\
\hline SP2 & 0.737 & & TBI2 & 0.903 & \\
\hline SP3 & 0.689 & & TBI3 & 0.879 & \\
\hline SP4 & 0.867 & & & & \\
\hline SP5 & 0.784 & & & & \\
\hline $\mathrm{TBc} 1$ & 0.773 & 0.851 & \multicolumn{2}{|l|}{$\begin{array}{l}\text { Trusting Belief } \\
\text { Dimension }\end{array}$} & $\mathrm{n} / \mathrm{a}$ \\
\hline $\mathrm{TBc} 2$ & 0.826 & & Competence & 0.884 & \\
\hline $\mathrm{TBc} 3$ & 0.843 & & Benevolence & 0.753 & \\
\hline TBc4 & 0.661 & & Integrity & 0.600 & \\
\hline$\chi^{2} / d f=$ & $43(d f=129)$ & $=0.923$ & $\mathrm{I}=0.841$ & $\mathrm{~A}=0.081$ & \\
\hline
\end{tabular}

Table 2. Average Variance Extracted (AVE) and Construct Correlations

\begin{tabular}{llllc}
\hline & AVE & PP & SP & TB \\
\hline Perceived & 0.797 & $\mathbf{0 . 8 9 2}$ & \\
$\begin{array}{l}\text { Personalization(PP) } \\
\text { Social Presence(SP) }\end{array}$ & 0.882 & 0.565 & $\mathbf{0 . 9 3 9}$ & $\mathbf{0 . 9 7 4}$ \\
Trusting Beliefs(TB) & 0.949 & 0.930 & 0.811 & \\
\hline & Note: Square root of AVE in bold on the diagonal. The AVE for each construct was $>.5$ as \\
recommended. The square root of the AVE for each construct was also $>$ the correlations \\
with other constructs as recommended.
\end{tabular}


Table 3. Hierarchical regressions for mediation tests $(\mathrm{N}=114)$

\begin{tabular}{lllll}
\hline Variable & Model 1 & Model 2 & Model 3 & Model 4 \\
\cline { 2 - 5 } & $\begin{array}{l}\text { Social } \\
\text { Presence }\end{array}$ & $\begin{array}{l}\text { Trusting } \\
\text { Beliefs }\end{array}$ & $\begin{array}{l}\text { Trusting } \\
\text { Beliefs }\end{array}$ & $\begin{array}{l}\text { Trusting } \\
\text { Beliefs }\end{array}$ \\
\hline Control & & & & \\
Gender & -0.041 & 0.135 & 0.180 & 0.138 \\
Age & -2.09 & -0.213 & -0.054 & -0.153 \\
Education & 0.009 & 0.023 & -0.049 & 0.022 \\
Hours on the internet & -0.065 & -0.13 & 0.009 & 0.006 \\
per day & & & & \\
Shopping Frequency & 0.125 & -0.05 & -0.063 & -0.084 \\
$\mathrm{R}^{2}$ & 0.232 & 0.037 & 0.193 & 0.193 \\
Perceived personalization & $0.548^{* * *}$ & $0.608^{* * *}$ & & $0.440^{* * *}$ \\
$\mathrm{R}^{2}$ & $0.529^{* * *}$ & $0.452^{* * *}$ & & \\
Social Presence & & & $0.502^{* * *}$ & $0.311^{* * *}$ \\
$\mathrm{R}^{2}$ & & & $0.624^{* * *}$ & $0.745^{* * *}$ \\
\hline$* p<0.05$ & $* * p<0.01$ & $* * * p<.001$ & & \\
\hline
\end{tabular}

\section{Discussion}

The experimental results show that, the recommending pages with two different levels of personalization arouse different perceived social presence and trusting beliefs towards online store. The higher the level of personalization that the users perceive, the stronger the perception of social presence, and the greater the trust towards the online store the consumers would have. The mediating effect of social presence is significant for the design of recommendation system.

Theoretical contributions of this study would be as follows. First, for users, personalization is a kind of psychological perception and evaluation of goal relevance. The greater the relevance to self needs, the higher the level of personalization he/she perceives. Second, personalized recommendations can directly affect trusting beliefs towards online store, and also affects indirectly by improving users' emotional experience. Third, perception of social presence is crucial for trust building process. Past researches mainly focus on improving the credibility of recommendation in order to enhance trust, while this study adds the social and affective influence of personalized recommending.

This study has several limitations. Our samples are composed only of undergraduate students. Future research should include participants within a more diverse range of age, online shopping experience and computer experience. And the personalized recommendation concerned in this paper is not a real one generated by a computer system. Therefore, the ecological validity of the experiment is affected.

Nonetheless, this study has already demonstrated the importance of personalized recommendation in terms of social impact. Managers who provide personalized recommendations on their online store should give concern to users' perception of social 
presence generated in the interaction with website. In addition, personalized recommendations might have different effects in combination with some social network elements and other environmental or psychological factors that might influence the social impact of personalized recommendations, which are all worthwhile for further investigation in the future.

Acknowledgements. This study was partially supported by the Knowledge Innovation Project of the Chinese Academy of Sciences (No. KSCX2-EW-J-8, 2011 2013), and the Special Fund for Beijing Key Discipline Construction (Applied Psychology, 2008 2012).

\section{References}

1. Liang, T.P., Li, Y.W., Turban, E.: Personalized Services as Empathic Responses: the Role of intimacy. In: PACIS vol. 73 (2009)

2. Tam, K.Y., Ho, S.Y.: Understanding the Impact of Web Personalization on User Information Processing and Decision Outcomes. MIS Quarterly 30, 865-890 (2006)

3. Gefen, D., Straub, D.W.: Consumer Trust in B2C E-Commerce and the Importance of Social Presence: Experiments in E-Products and E-Services. Omega 32, 407-424 (2004)

4. Hess, T., Fuller, M., Campbell, D.: Designing Interfaces with Social Presence: Using Vividness and Extraversion to Create Social Recommendation Agents. Journal of the Association for Information Systems 10, 889-919 (2009)

5. Tam, K.Y., Ho, S.Y.: Web Personalization As A Persuasion Strategy: An Elaboration Likelihood Model Perspective. Information Systems Research 16, 271-291 (2005)

6. Xiao, B., Benbasat, I.: E-Commerce Product Recommendation Agents: Use, Characteristics, and Impact. MIS Quarterly 31, 137-209 (2007)

7. Kumar, N., Benbasat, I.: The Influence of Recommendations and Consumer Reviews on Evaluations of Websites. Information Systems Research 17, 425-439 (2006)

8. Choi, J., Lee, H.J., Kim, Y.C.: The Influence of Social Presence on Evaluating Personalized Recommender Systems. In: PACIS (2009)

9. McKnight, D.H., Choudhury, V., Kacmar, C.: The Impact of Initial Consumer Trust on Intentions to Transact with A Web Site: A Trust Building Model. Journal of Strategic Information Systems 11, 297-323 (2002)

10. Komiak, S.X., Benbasat, I.: The Effects of Personalization and Familiarity on Trust and Adoption of Recommendation Agents. MIS Quarterly 30, 941-960 (2006) 